Evangelina Soltero Sánchez Evangelina Soltero Sánchez es profesora de Literatura Hispanoamericana de la Universidad Complutense de Madrid. Entre sus líneas de investigación destacan las siguientes: Literatura Femenina Hispanoamericana (sobre la que imparte un curso de doctorado), Literatura y Fotografía y Relaciones Culturales España y América. Su tesis doctoral versó sobre la obra de María Enriqueta Camarillo.

La fotografía consiguió algo más: neutralizar el concepto de belleza. Todo es «bello» si está impreso en papel fotográfico, porque lo feo al convertirse en público adquiere inmediatamente categoría de digno, y lo digno está «bien considerado».

2

Realmente se realizaron, poco antes, unas pruebas fotográficas en el Puerto de Veracruz.

3

La llegada a otros países fue desigual; antes que a México llegó a Uruguay, dónde se fecha el primer daguerrotipo hacia abril de 1839, antes que en Estados Unidos; como contraparte tenemos el caso nicaragüense de donde no se tiene constancia de su presencia hasta 1858.

4

La interesante antología de $\mathrm{Xa}$ vier Moyssén, La crítica de arte en México (México, UNAM-Instituto de Investigaciones Estéticas, 1999, 2 vols.) recoge los siguiente artículos: «La primera exposición de arte fotográfico en México», Arte y Letras, Año VIII, n 247, México, 17 de diciembre de 1911 (en vol. I, pp. 560-561); de José G. Zuno, «El fotógrafo de las bellas tapatías», El Universal llustrado, $\mathrm{n}^{\circ} 98$ México, 21 de marzo de 1919 (en vol. II, p.246), y de Carlos Mérida, "Retratista mexicanos», EI Universal Ilustrado, México, 15 de septiembre de 1920 (en vol. II, pp. 426-427).

\footnotetext{
Apunten, disparen, flash: Elen Poniatowska / Víctor Casasola y Manuel Álvarez Bravo

EVANGELINA SOLTERO
} SÁNCHEZ

\title{
APUNTEN, DISPAREN, FLASH: ELENA PONIATOWSKA / VÍCTOR CASASOLA Y MANUEL ÁLVAREZ BRAVO
}

\author{
EVANGELINA SOLTERO SÁNCHEZ \\ Universidad Complutense de Madrid
}

Para entender las relaciones que Elena Poniatowska establece con los fotógrafos mexicanos del siglo XX considero necesario realizar un breve repaso por la historia de este arte en México.

\section{MÉXICO Y LA FOTOGRAFÍA}

Corrían los primeros días del año 1839 cuando Louis Daguerre se presentaba y presentaba en la Academia de Ciencias Francesa su invento, el daguerrotipo. El inventor francés ofrecía al mundo la posibilidad de cumplir un sueño: poseer eternamente una imagen objetiva y natural en la que la mano del hombre no participaba. El «espejo con memoria» (mirror with a memory, como se le denominó en el siglo XIX) sería la máquina que evitaría la interpretación, permitiendo la obtención de

5

Destacan entre otros nombres como los de los ingleses Seager y Catherwood; los estadounidenses Hasley, John Lloyd Stephens; el músico francés Alfred Bablot fundador en 1851 de la primera publicación sobre fotografía, Le Daguerréotype, y sus compatriotas Charnay y Briquet; el húngaro Pál Rosti; el alemán Wöikof, así como el padre de Frida Kahlo, Guilleromo Kahlo (hacia 1891); los austriacos Emanuel von Friederichsthal (alumno de Humboldt) y Maler, entre otros.
6

Los primeros fotógrafos mexicanos con nombre y apellidos fueron Julio María y Campos, Andrés Martínez, Octaviano de la Mora, Carlos Barriere, Romualdo García o Natalia Baquedano (la primera mujer que abrió un estudio fotográfico hacia 1890). Un completo estudio de la fotografía mexicana es el realizado por Olivier Debroise: Fuga mexicana. Un recorrido por la fotografía en México, México, Consejo Nacional para la Cultura y las Artes, 1998. un retrato exacto de la «realidad» de manera rápida y económica, una industrialización de la imagen física ${ }^{1}$.

El invento corrió como la pólvora por Europa, y su llegada a América fue inmediata. Desde esa presentación oficial en enero de 1839 hasta el primer daguerrotipo realizado en Estados Unidos sólo transcurrieron nueve meses. La llegada al resto de los países América no se hizo esperar mucho más, y el 26 de enero de 1840 se realizaba el primer daguerrotipo oficial en México, una vista de la Catedral de la capital ${ }^{2}$.

Aunque la presencia de la cámara oscura fue anterior en otras latitudes de la América hispana ${ }^{3}$, fue México el lugar en el que la fotografía despertó más interés y alcanzó una producción importante y de gran calidad. El respeto que demostró la alta cultura mexicana hacia esta nueva forma de reproducción de imágenes quedó demostrada en distintos artículos críticos sobre arte, en los que se reseñaba las exposiciones fotográficas que organizaban distintas instituciones ${ }^{4}$.

Los primeros años de la fotografía mexicana se centraron en la fijación de exteriores y sus realizadores fueron, en mayor número, estadounidenses, alemanes, ingleses, franceses y húngaros ${ }^{5}$; los fotógrafos nacionales comenzaron a surgir hacia $1860^{6}$. Los primeros utilizaron sus objetivos para el registro etnográfico de ruinas precolombinas y construcciones coloniales; los segundos se dedicaron principalmente a desarrollar la fotografía comercial. 
LOS OJOS DE MÉXICO. CASASOLA Y ÁLVAREZ BRAVO

Habrá que esperar al porfiriato y, especialmente, a la Revolución para encontrar una fotografía propiamente nacional, o al menos, la fotografía que crea la imagen de lo genuinamente mexicano. Ésta vendría de la mano del que se puede considerar uno de los fotógrafos -y el coleccionista de fotografía- más importante y valioso de México, Agustín Víctor Casasola. Nacido el 28 de julio de 1874, comienza a trabajar desde muy joven en talleres tipográficos y a los veinte años da inicio a su carrera profesional como reportero siendo a final de siglo XIX un fotógrafo establecido. Tras fundar en 1912 una agencia fotográfica que tenía como lema la frase «Tengo o hago la foto que usted necesite», ofreció sus servicios a periódicos, revistas y al público en general, incorporando a la agencia tanto a su familia como a otros profesionales del ramo.

Consciente del poder de la imagen fotográfica, precisamente por su supuesta capacidad de registro fidedigno, desde joven inicia un proyecto que no abandonaría jamás y que sin duda se transformaría en obsesión: formar un archivo fotográfico al servicio de la historia de México. En los años veinte la vocación histórica del archivo Casasola era evidente. Publicaba regularmente una página completa con una especie de reportaje sobre temas del pasado: hechos políticos de importancia, estampas nostálgicas de la vida cotidiana, fiestas $\mathrm{y}$ actos sociales o religiosos. Desde ese momento sus fotografías dejaron de ser noticias y se convirtieron en una referencia ineludible del pasado mexicano.

Casasola consignó por medio de la fotografía los últimos años del gobierno de Porfirio Díaz y siguió incansable, y aun a riesgo de su vida, todo el proceso revolucionario. Se convierte así en un pionero del reportaje y de la fotografía documental y/o testimonial, estilo que ha caracterizado a la fotografía mexicana del siglo XX y a parte de su literatura (la de Poniatowska es un buen ejemplo de ello). Las instantáneas de los soldados y de las soldaderas, de las batallas entre las fuerzas revolucionarias y las del ejército, de Zapata triunfante y de Zapata muerto, o las imágenes de los últimos instantes de las vidas de muchos fusilados fueron atrapadas por el objetivo de este periodista que no sólo ilustró la historia de la Revolución, también escribió el capítulo más importante de la historia de la fotografía mexicana. Asimismo los trenes,

soldados, rifles, sombreros de anchas alas, cananas, caballos, polvaredas y "chinas» que residen en el imaginario mexicano y no mexicano se deben a las fotografías de Casasola.

Su cámara fotográfica fue usada como instrumento social, siguiendo la línea temática de sus contemporáneos estadounidenses que se sirvieron del objetivo como medio de denuncia social7. Captó actos de violencia con un realismo y una sensibilidad muy alejados de la glorificación implícita en muchos cuadros pictóricos, y se convirtió en el heredero de un motivo fotográfico que tuvo su nacimiento en México: la fotografía de guerra ${ }^{8}$.

Si Casasola fue el fotógrafo de la historia del país en la última década del siglo XIX y las dos primeras del siglo XX, finalizada la Revolución mexicana, surge una nueva forma de mirar tras la cámara, la cual se encargará de componer la intrahistoria de la república. Hacia 1920 nace para la fotografía mexicana otra gran figura, Manuel Álvarez Bravo, cuya obra se caracteriza por la muestra de un México no oficial, en el que los nadies y las nadas ${ }^{9}$ ocupan un lugar oficial en el imaginario nacional.

\section{ELENA PONIATOWSKA, IMAGEN Y PALABRA}

Dejó aquí en suspenso la trayectoria profesional de Álvarez Bravo, que retomaré a lo largo del artículo, para entrar en lo que nos compete, la obra literaria de Elena Poniatowska en torno a la fotografía. Las relaciones de la escritora mexicana con el mundo fotográfico mexicano se traduce en un importante número de títulos ${ }^{10}$; dos son los que me interesan traer aquí y realizar un análisis más pormenorizado: Manuel Álvarez Bravo. El artista, su obra, sus tiempos $(1991)^{11}$ y Las soldaderas $(1999)^{12}$.

Las razones para elegir estos dos libros son varias: las fotografías que se publican tienen como autores los dos fotógrafos más carismáticos e internacionales de la fotografía mexicana, Casasola y Álvarez Bravo; ambos, como se ha recordado más arriba, han creado una imagen nacional del México del siglo XX (de manera más voluntaria en el caso de Casasola, de modo más casual en el de Álvarez Bravo); el número de fotógrafos

\footnotetext{
7

Ejemplo de este uso de la fotografía en Estados Unidos lo tenemos con Jacob Iris que, hacia 1880, tomó
}

una serie de instantáneas en las que se mostraban las condiciones de vida en los barrios miserables de Nueva York; su campaña con la

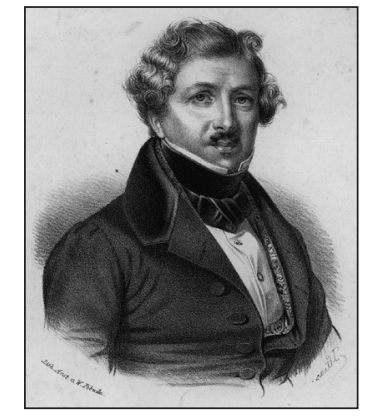

Lovis Daguerre.

cámara y con la pluma aceleró la aplicación de mejoras largamente esperadas. De igual modo, el sociólogo norteamericano Lewis Hine fotografió, de 1905 a 1930, a los niños que trabajaban en las fábricas, imágenes que propiciaron la aprobación de una ley que prohibía la explotación de los niños.

8

La primera fotografía de guerra es de 1847 (México-Estados Unidos, 1846-1848). Las siguientes fotografías de guerra fueron tomadas por Fenton en 1855 durante la Guerra de Crimea. Estados Unidos realizó las primeras de su historia durante la Guerra de Secesión (Brady en 1865).

9

Gente común, objetos cotidianos - peculiares de cada zona de México -la de Oaxaca de manera más insistente-, naturaleza descargada de reminiscencias exóticas han sido captadas por su cámara desde que comenzara su labor como fotógrafo en plena juventud, hasta casi su muerte, en 2002.

10

En la Bibliografía, el lector encontrará la relación de los mismos, con la seguridad de que habrá omisiones.

11

Manuel Álvarez Bravo y, Elena Poniatowska, Manuel Álvarez Bravo. El artista, su obra, sus tiempos, México, Banamex, 1991 ; las citas referentes al texto se harán por esta edición.

12

Elena Poniatowska, La soldaderas, México, Ediciones Era-Conaculta/INAH, 1999 (2 ${ }^{a}$ reimp. 2003); las citas referentes al texto se harán siguiendo la reimpresión.

Apunten, disparen, flash: Elena Poniatowska / Víctor Casasola y Manuel Álvarez Bravo

EVANGELINA SOLTERO SÁNCHEZ 


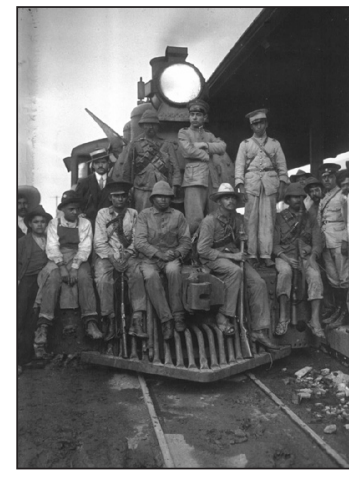

Foto hecha por Víctor Casasola.

13

Las diferencias entre un lenguaje masculino y un lenguaje femenino tanto en el ámbito de la literatura como en el de otras formas de expresión artística (por lo que afecta a este artículo, en fotografía) es algo que no se discutirá en profundidad en este texto, aunque se tocará inevitablemente.

14

Antonio Ortiz Mena, «Presentación», en Poniatowska, Manuel Álvarez Bravo..., op. cit., p. 7.

15

Poniatoswka, Las soldaderas, op. cit., p. 25.

16

Poniatowska, Manuel Álvarez

Bravo..., op. cit., p. 47

17 Es destacable en este fragmento el hecho de que Elena Poniatowska se sirva de un recuerdo de su propia infancia para transmitir los sentimientos que en ella provoca Álvarez Bravo.

18

Así denominó Diego Rivera la fotografía de Álvarez Bravo (Poniatowska, Manuel Álvarez Bravo..., op. cit., p. 41)

Apunten, disparen, flash: Elen Poniatowska / Víctor Casasola Manuel Álvarez Bravo

EVANGELINA SOLTERO SÁNCHEZ en la obra de Poniatowska es menor que el de fotógrafas, lo cual permite analizar las relaciones entre un lenguaje visual masculino y una escritura femenina ${ }^{13}$; por último, el origen creativo de cada libro es diferente, lo cual debería conllevar una estructuración y un lenguaje distintos.

Al inicio de la década del 90, el Banco Nacional de México, dentro de su política de difusión de la cultura mexicana dentro y fuera de sus fronteras, auspicia un catálogo fotográfico en torno a la obra de Manuel Álvarez Bravo (para entonces, el fotógrafo contaba con ochenta y ocho años); será él mismo el que seleccione el material que ha de conformar el libro. Asimismo, la institución editora solicita a Elena Poniatowska que escriba un texto sobre la vida y obra de Álvarez Bravo «que sirv[a]n de hilo conductor» ${ }^{14}$. A finales de la misma década, Poniatowska cumple una vez más con uno de los objetivos fundamentales de su escritura: que su palabra escrita sea voz pública de aquellos seres que por su condición marginal no tienen acceso a la historia oficial; con la voluntad documental y reivindicativa que siempre le ha caracterizado escribe Las soldaderas -revisión, reivindicación y dignificación de las mujeres mexicanas que participaron en la Revolución Mexicana-, texto acompañado de fotografías del Fondo Casasola seleccionadas por la autora.

Ambos textos, y sus respectivas fotos, permiten a la escritora realizar un repaso histórico al México del siglo XX. La foto más antigua es el retrato de una joven vestida de blanco con sombrero y cartuchera, perteneciente al Fondo Casasola y fechada entre 1905-1910, época aún de la «paz porfiriana» pero con la que Poniatowska deja constancia visual de la presencia femenina en el mundo militar de la república y recuerda que

Antes de la Revolución, durante el porfiriato, el ejército mexicano era más bien pasivo. Díaz decretó algunas reformas militares pero no eliminó la participación de las soldaderas. Su tarea principal, entonces, consistió en alimentar a los hombres ${ }^{15}$.

La foto más actual, «Espejos con Laura y Echécatl», es autoría de Álvarez Bravo (fechada en 1990) y en ella se visualiza un desnudo femenino indirecto al ser fotografiada la imagen reflejada en dos espejos superpuestos, mostrando

Sus mujeres desnudas, mujeres ensimismadas, impávidas, posan en estado de lucidez, detenidas y juzga- das dentro del tiempo y el espacio, en un plazo que sólo Manuel determina.[...] De estas modelos, sólo habla la luz sobre sus cuerpos, formas que son bloques de poder como los de ahora dividen al mundo. La luz de Manuel los unifica. Lo demás no existe ${ }^{16}$.

Un retrato de mujer vestida y armada inicia el viaje de Poniatowska por la historia de México; un retrato de mujer desnuda -con la ayuda involuntaria de Álvarez Bravo- cierra ese recorrido. Sin quererlo, o quizás queriéndolo, la historia de este México que nos ofrece la escritora se simboliza a través de la liberación de la mujer en el imaginario fotográfico mexicano.

La estructura de los dos títulos posee, se podría decir, una condición fotográfica al dividirse en pequeños fragmentos de contenido autónomo que no por ello dejan de mantener un diálogo con el resto de los fragmentos, y con las fotos que acompañan al final (en ambos libros las fotografías aparecen en sucesión tras el texto escrito, 84 de Álvarez Bravo y 50 del Fondo Casasola). Pese a esta aparente similitud, existen diferencias que, considero, vienen dadas por la condición de «libro encargo» (el de Álvarez Bravo) y «libro voluntario» (el de las soldaderas). En el caso de Manuel Álvarez Bravo..., Poniatowska escribe veinticinco pequeños textos encabezados con un título que hace referencia a algún elemento del acto fotográfico o alguna característica de la fotografía de Álvarez Bravo; sirvan como ejemplo "Camera obscura», «El daguerrotipo», «El nitrato de plata», «Tú, aprieta el botón», «La realidad a secas» $\mathrm{o}$ «El viejecito de las vistas» ${ }^{17}$. Por el contrario, en el libro dedicado a las soldaderas, los doce fragmentos que lo forman no son titulados y la separación entre uno y otro es indicada con un rombo tipográfico.

\section{MANUEL ÁLVAREZ BRAVO Y LA «FOTOPOESÍA»18}

El primero debe referir la biografía de Álvarez Bravo y su contexto (es el objetivo a cumplir y para el que ha sido solicitada por la editorial). Pero, ¿cómo relatar una biografía sin caer en el discurso oficializado de las biografías? La respuesta a esta pregunta la da Elena Poniatowska a través de la estructuración del texto en esos pequeños fragmentos/ fotos que además se convienen con su estilo oral/conversacional; de este modo nos cuenta cómo ha sido y es el fotógrafo, por dónde se movió, a quiénes conoció, qué fotografió, 
por qué necesita fotografiar; sigue en todo momento una característica que le es consustancial al hecho fotográfico, contar lo que no se ve en la foto pero que se infiere de ella, o en palabras de Cortázar:

[...] la de recortar un fragmento de la realidad, fijándole determinados límites, pero de manera tal que ese recorte actúe como una explosión que abre de par en par una realidad mucho más amplia, como una visión dinámica que trasciende espiritualmente el campo abarcado por la cámara ${ }^{19}$.

Y también se aviene al estilo de Álvarez Bravo a la hora de titular sus fragmentos/fotos, que se caracteriza por nombrarlas por aquello que no está, pero que se ve. Y mejor verlo con un ejemplo: en la fotografía «Las lavanderas sobreentendidas» ${ }^{20}$ lo que se ve son unos magueyes medio cubiertos por sabanas tendidas; el comentario de esta foto por parte de la escritora aparece en el primer fragmento del libro titulado «Tú, aprieta el botón», y en el cual Poniatowska reflexiona sobre uno de los rasgos más importantes del arte fotográfico del Álvarez Bravo, la capacidad de éste de fotografiar lo invisible:

Saint-Exupéry dijo alguna vez que sólo lo esencial es invisible. ¿El viento se puede retratar? Los árboles movidos por él, los tallos curvándose, los maizales ondulantes, sí, pero ¡el viento? ¿El viento en sí? Manuel Álvarez Bravo toma a "Las lavanderas sobreentendidas", no hay una lavandera ni por equivocación y si las hubo ya se fueron. Sólo dejaron la ropa tendida al sol sobre la punta de los magueyes. [...] Sólo Manuel ha tomado lo invisible, lo que no estaba allí, ni va a estar nunca ${ }^{21}$.

$O$ en «Nitrato de plata», donde el título hace referencia al elemento químico que $\mathrm{Da}$ guerre necesitó para conseguir que la imagen se fijara en la placa y en el texto se comentan características de la fotografía de Álvarez Bravo que han dejado huella en las generaciones posteriores.

Títulos de fotos y fragmentos hablan de lo que nunca puede estar pero que se ve: el alma de las cosas, lo que encierran en su interior, imposible de cifrar pero sí de provocar sensaciones. De este modo va realizando la escritora 25 fragmentos/fotos que va titulando no tanto por lo que cuenta como por lo que podemos colegir de ello. Y esas fotos escritas no siguen un orden cronológico, sino que, como artista que es, va disparando aquí y allá según llaman su atención determinados momentos

de la vida de Álvarez Bravo, determinados personajes de la historia de México que le acompañaron, determinados escritores que le influyeron ${ }^{22}$, o determinadas declaraciones hechas por el fotógrafo.

En cuanto a esto último, hay que destacar también como rasgo característico en el estilo escritural de Poniatowska la entrega de voz al personaje biografiado ${ }^{23}$. Ello ocurre en el fragmento «Los rostros y los gestos reveladores» en el que Álvarez Bravo nos confiesa la influencia que ejerció sobre su concepto de la fotografía el muralismo; parte de «La realidad a secas» en la que comunica su idea de la vida y el arte y la necesidad de la calle para explicar su arte; en «El alto rango de la fotografía» donde desarrolla la idea de que su aproximación a la fotografía está íntimamente relacionada con la vida de las calles del centro de México; en «La buena fama durmiendo» -título asimismo de una fotografía del mexicano- fragmento en el que a través de un diálogo conocemos cómo se cocinó la foto que Breton le encargara para la portada del catálogo de la Exposición Surrealista de 1939; y por último, el último, «La sal», en el que Poniatowska nos ofrece una imagen límpida del presente del fotógrafo:

A los ochenta y ocho años Manuel se pregunta: "¿Por qué quieren que vuelva la cabeza al pasado si a mí lo que me interesa es el futuro? A los ochenta y ocho años sigo en el presente con la vista al futuro, con los pies en la tierra, como dice el título de una de mis fotografías. Los problemas cotidianos y los problemas del oficio son tantos que ipara qué estar viendo lo que pasó? El día que se vive es importante y lo que se tiene que hacer es lo necesario. Lo que espero para el futuro es seguir trabajando, que la mata siga dando ${ }^{24}$.

Fotos y textos dibujan la calle, sus gentes, sus objetos, sus motivos en las imágenes; su expresiones coloquiales, sus diminutivos ${ }^{25}$, sus dobles significados lingüísticos, sus diálogos en los fragmentos. Fotógrafo y escritora se colocan en el margen y desde él hablan; ambos se sienten impelidos hacer de ese margen el centro de sus creaciones, colocar ante los ojos lo que no se ve o no se quiere ver, «un

19

Julio Cortázar, "Algunos aspectos del cuento», en La casilla de los Morelli, Barcelona, Tusquets, 1988 (4 $4^{a}$ edc) p. 137.

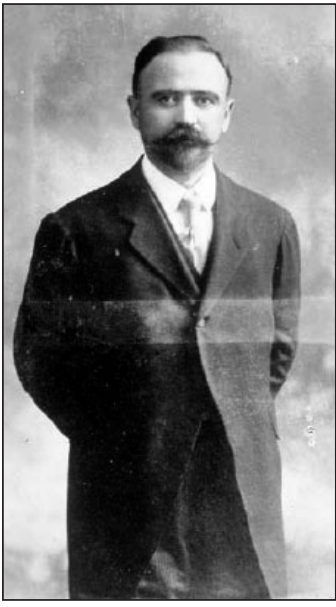

Madero fotografiado por Casasola.

20

Poniatowska, Manuel Álvarez Bravo..., op. cit., foto 17.

21 Ibid., p. 13.

22

La nómina de personajes del mundo del arte y la política del México de las décadas del 30 y 40 es extensa, entre ellos los fotógrafos Tina Modotti, Edward Weston, Carleton Beals, Pablo O'Higgins, Emily Edwards, Henri Cartier-Bresson; políticos como Lázaro Cárdenas, José Vasconcelos, Trotsky o Víctor Raúl Haya de la Torre; los pintores y muralista Frida Khalo, Rivera Siqueiros, Orozoco, Tamayo escritores como André Breton, Antoni Arataud, T.H. Lawrence, Julio Torri, Xavier Villaurrutia Octavio Paz; el cineasta Sergei Eisenstein, etc.

23

También entrega su voz y escritura a Diego Rivera en el fragmento «El aceite de lavanda» en el que se reproduce un fragmento crítico del muralista al fotógrafo.

24

Poniatowska, Manuel Álvarez Bravo..., op. cit., p. 57

25

Ejemplos de usos del diminutivo se encuentran hasta en los títulos de los fragmente, así «El agujerito", en el que se comenta desde dónde ve la realidad el fotógrafo.

Apunten, disparen, flash: Elen Poniatowska / Víctor Casasola y Manuel Álvarez Bravo

EVANGELINA SOLTERO SÁNCHEZ 


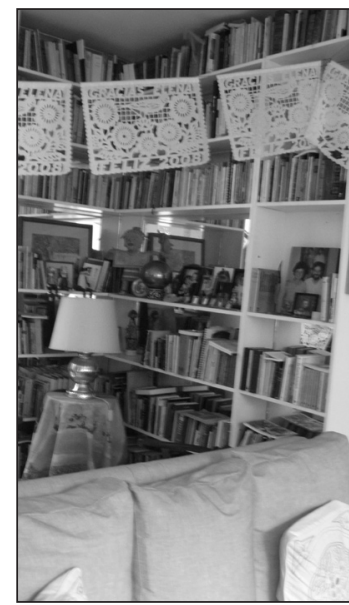

Casa de Elena Poniatowska.

26

Ibíd., p. 55.

27

Id., p. 35 . mirar que nadie mira» ${ }^{26}$; es una obligación del artista, tal y como lo declara Álvarez Bravo:

[...], así como todo en la vida es de encargo, no es un encargo explícito, sino es un encargo de la sociedad en la que vivimos. ¿Cómo podríamos aislarnos de la sociedad? Por eso, mi obra también es de encargo»"

EN EL AMOR Y EN LA GUERRA. DIGNIFICACIÓN DE LAS SOLDADERAS

Ateniéndonos a la declaración de Álvarez Bravo sobre la condición del artista y del arte, el segundo libro que nos ocupa, Las soldaderas, también sería de encargo aunque en un principio lo definiera como «libro voluntario». En este caso se inscribiría dentro de ese «encargo de la sociedad» con la que Elena Poniatowska y su literatura siempre se ha sentido comprometida.

En Las soldaderas, la escritora realiza un repaso histórico de esta figura habitual en el mundo militar mexicano. A través de doce fragmentos, el lector va viendo pasar ante sus ojos estos singulares personajes que participaron activamente en la Revolución Mexicana y que, sin embargo, no se vieron reflejados en la historia de México. El objetivo básico del texto es la dignificación de un mundo femenino que, por lo general, fue calificado de manera negativa por todos las facciones revolucionarias (la paradoja es que en todas ella existían soldaderas), soliviantado y, terminado el proceso revolucionario, olvidado.

Elena Poniatowska ofrece distintas visiones de la soldadera desde diversos ámbitos institucionales: el político, el legislativo (antes, durante y después de la Revolución), el pictórico, el literario, el musical, el cinematográfico y, por supuesto, el fotográfico. A lo largo del libro algunos de los nombres más re-conocidos de la historia mexicana del siglo $\mathrm{XX}$ aparecen dibujados en relación con aquellas mujeres: los políticos Pancho Villa, Emiliano Zapata, Venustiano Carranza y Porfirio Díaz; los escritores Mariano Azuela, Rafael F. Fuentes, Heriberto Frías, Martín Luis Guzmán, Gregorio López y Fuentes, José Rubén Romero, Ignacio L. Urquizo, José Vasconcelos, Mauricio Magadaleno, Francisco Rojas Gonzáles, Miguel N. Lira, Carlos Fuentes, Elena Garro, Juan Rulfo, Rosa E. King; los pintores Clemente Orozco, Rufino Tamayo, David Alfaro Siqueiros, Diego Rivera, José Guadalupe Posada, Roberto Montenegro, Manuel Rodríguez Lozano, Juan Soriano; los grabadores Andrea Gómez, Mariana Yampolsky, Elena Huerta, Sara Jiménez, Alfredo Zalce, Fernando Castro Pacheco, Jesús Escobedo, Fernando Leal, Alberto Beltrán; los directores y actores Salvador Toscana, Emilio el Indio Fernández, Gabriel Figueroa, Pedro Armendáriz, María Félix; los músicos Baltasar Dromundo, Julián Reyes, Vicente T. Mendoza, Silvestre Revueltas; los ensayistas y periodistas Friedrich Katz, John Womack, Eric Wolf, Anita Bremer, John Reed, Elizabeth Salas, Evangelina Enríquez, Enmanuel Carballo, Antonio Castro Leal; y los fotógrafos Víctor Casasola y Jorge Guerra. Esta nómina se da cita en las justas 20 páginas que conforman el texto del libro.

Con todos ellos y ellas, Elena Poniatowska va componiendo un inmenso mural dedicado exclusivamente a las soldaderas; un mural que transmite a menudo un desdén, cuando no un desprecio (es el caso de Villa, Orozco); que en otras ocasiones las idealiza al punto de convertirlas en criaturas angelicales capaces de provocar el amor más intenso (las soldaderas que transmiten muchos de los corridos, siendo el mejor ejemplo de ellos «Adelita»); que en unas ocasiones es representada con rasgos masculinos, como en la película Juana Gallo, y en otras son adornadas con todos las virtudes de la femineidad, como la dibuja el filme Enamorada-paradójicamente ambos personajes interpretados por María Félix. Por último, la mitología azteca posee imágenes en las que el mundo femenino contiene los rasgos de la lucha representado en Coyolxauhqui o la Coatlicue (madre del Dios de la Guerra).

Pero para que la visión de la soldadera adquiera tintes de realidad y equilibrio, Poniatowska se sirve de las fotografías realizadas por Casasola durante la Revolución. Las mujeres fijadas en las placas de gelatina se caracterizan por su normalidad, su solidaridad para con los hombres a los que acompañan y su sentido del sacrificio, o en palabras de la escritora:

La soldadera se encargaba de hacer las previsiones necesarias. Trabajar para un soldado se convirtió, rápidamente, en una manera de ganarse la vida y mantener a sus hijos. Como las sirvientas, las soldaderas eran libres; podían irse a la hora que se le antojara, acompañar a los soldados por el país o cambiar de hombre a voluntad. Algunas incluso seguían a la tropa para venderle carne seca, hacer sus tortillas y cocer sus frijoles y, como no tenían a ningún hombre en especial, prostituirse si se daba el 
caso. Sin embargo, la mayoría tenía a sus hombres y era fiel a carta cabal ${ }^{28}$.

Junto a la fotografía, la literatura es el campo desde el que la autora más observa a la mujer soldado. El inicio del propio libro refleja esa preocupación por cómo la ficción recoge el mundo de las soldaderas al reproducir un fragmento del cuento "Un disparo al vacío» de Rafael F. Muñoz ${ }^{29}$. El relato se hace eco de un hecho acaecido en 1916 en la estación de ferrocarril de Santa Rosalía (Chihuahua) donde un grupo de noventa soldaderas carrancistas son ejecutadas por las tropas villistas. De este modo, la primera visión que la autora ofrece es la de la vejación, en un mundo de hombres que las consideran un estorbo, como se infiere de las palabras de Villa en el relato:

Una mujer vieja, picada de viruelas, levantó el brazo y gritó:

- Todas... ¡Todas quisiéramos matarte!

El cabecilla retrocedió.

- ¿Todas?. Pues todas morirán antes que yo [...]

Y en el momento en que las cubrías las llamaradas, Villa todavía escuchó una voz ronca que gritaba desde la pira:

- ¡Perro, hijo de perro, habrás de morir como perro! $[\ldots .$.

Los dorados regresaron a la población en silencio, hasta que el hefe habló:

- ¡Qué diantres de mujeres tan habladoras! ¡Cómo me insultaron! Ya me comenzaba a dar coraje. ${ }^{30}$

Esta cosificación de la figura femenina que puede traducirse del tratamiento de Villa no fue exclusivo del Centauro del Norte. Venustiano Carranza, tras aprovechar el apoyo que las soldaderas brindaron a las fuerzas carracintas y prometerles pensiones una vez llegara al poder, en 1917 olvidó dicha promesa; el desprecio es reproducido por Elena Poniatowska a través de la voz de Jesusa Palancares:

- Si estuvieras vieja te pensionaba el gobierno, pero como estás muy joven, cualquier días te vuelves a casar y el muerto no puede mantener al otro marido que tengas.

Jose-Jesusa, encolerizada, rompió su comprobantes y se los aventó a la cara a Venustiano Carranza:

- ¡Ah, cómo eres grosera!

- ¡Más grosero es usted! Más que grosero ladrón, porque le quita el dinero a los muertos. ${ }^{31}$

Estos dos ejemplos, el primero procedente de la literatura oficial y el segundo del género testimonial, sirven para darle al lector una idea del no-espacio público de la soldadera; el segundo, además, para poder completar el mural que Poniatowska va construyendo.

En la nómina literaria anterior hay dos nombres que, intencionadamente, no he dado: el de Jesusa Palancares (por extensión el de Elena Poniatowska) y el de Nellie Campobello. Ambas autoras son imprescindibles para obtener la imagen digna que de las soldaderas reivindica Poniatowska; ambas, igualmente, se hallan en los márgenes de la literatura oficial por lo que, de nuevo, el margen se convierte en centro del discurso. La marginalidad de Jesusa radica en su pertenencia a la cultura popular, ser soldadera y ser su texto testimonio oral trasladado al papel por un transcriptor (Elena); el lenguaje de Jesusa es el lenguaje de aquellas mujeres que debieron defenderse no ya de la guerra, sino de sí mismas. Poniatowska entrega algunos fragmentos a Palancares y es ella quien nos cuenta cuál era el trato recibido, cuáles sus funciones o por qué nombres fueron llamadas:

Según Jesusa, las mujeres de la Revolución fueron llamadas vivanderas, comideras, galletas de capitán, soldaderas, chimiscoleras, soldadas, juanas, cucarachas, argüenderas, mitoteras, busconas y hurgamanderas ${ }^{32}$.

Lenguaje el de Jesusa limpio y sin ambages que refleja la realidad de México.

La marginalidad de Nellie Campobello consiste en ser la única escritora de la novela de la Revolución y representar literariamente a la facción villista. Para fotografiar la imagen olvidada de Campobello, Poniatowska la presenta como una soldadera, en este caso del ejercito literario:

Nellie Campobello, la única autora de la novela de la Revolución, también es una soldadera. Va con la impedimenta, y los intelectuales de su época la usan o la menosprecian. Martín Luis Guzmán recibió el archivo de Francisco Villa que Nellie puso en sus manos y escribió así sus Memorias de Pancho Villa. En 1940, Nellie publicó su libro Apuntes sobre la vida militar de Francisco Villa, que no tuvo resonancia no por falta de méritos sino porque la autora no podía vencer su doble condición: mujer y mexicana $a^{33}$.

Reivindicar el lugar de la mujer en la historia a través de la figura de la soldadera es la meta que Elena Poniatowska se propone al principio de este libro. Todo lo que encierran sus páginas está al servicio de esa meta, inclui-
Relato publicado en la década del 30 y que se basa en informaciones recogidas del que fuera secretario de Pancho Villa, el coronel José María Jaurrieta. Jaurrieta habla de noventa mujeres, mientras que el texto de Muñoz reduce el grupo y son sesenta las mujeres ajusticiadas.

30

Poniatowska, Las soldaderas, op. cit., p. 10.

31

Ibíd., p. 12.

32

Id., p. 22. El término «juanas» ha de relacionarse con el de «juan» nombre genérico que se le daba al soldado raso revolucionario.

33

Id., p. 26. \begin{tabular}{c} 
Apunten, disparen, flash: Elena \\
Poniatowska / Víctor Casasola y \\
Manuel Álvarez Bravo \\
\hline EVANGELINA SOLTERO \\
SÁNCHEZ
\end{tabular} 


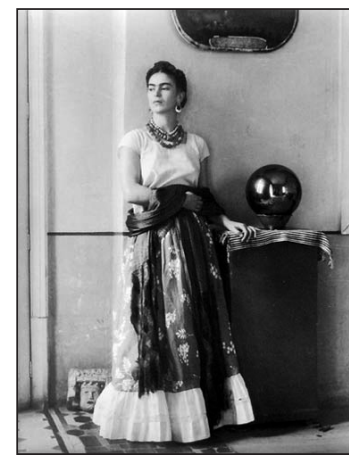

Frida Kahlo fotografiada por Manuel Álvarez Bravo.

34

Poniatowska, Manuel Álvarez Bravo..., op. cit., p. 37. das las fotografías. El lector podrá observar que los retratos elegidos van encaminados a ofrecer una imagen de sacrificio y entrega de las soldaderas; el lenguaje visual de Casasola se repliega a las necesidades de la palabra escrita e, irónicamente, la documentación visual del Fondo Casasola que ha servido para construir el imaginario nacional y oficial mexicano -eminentemente masculino- sirve, cuando es visto desde el margen -literatura femenina y testimonial- para construir el imaginario nacional femenino.

Literatura y fotografía en Elena Poniatowska, Víctor Casasola y Manuel Álvarez Bravo son instrumentos de los que se sirven para convertir la intrahistoria en historia, son herramientas de reivindicación social porque para los tres

[...] en la vida, todo tiene un contenido social, depende, claro, del que está mirando. La trascendencia que cualquier hecho pueda tener a través de la fotografía se la da el fotógrafo, es el fotógrafo el que le da su belleza dramática, su contenido político, su contenido social ${ }^{34}$.

Léase a la vez donde pone fotografía y fotógrafo, literatura y escritor.

\section{BIBLIOGRAFÍA}

Barthes, Roland. Notas sobre la fotografía, Barcelona, Piados, 1999.

Benjamín, Walter. Sobre la fotografía, Valencia, Pre-Textos, 2004.

Cortázar, Julio. «Algunos aspectos del cuento", en La casilla de los Morelli, Barcelona, Tusquets, 1988 (4a edc).

Debroise, Olivier. Fuga mexicana. Un recorrido por la fotografía en México, México, Consejo Nacional para la Cultura y las Artes, 1998

Dubois, Philippe. De la representación a la recepción, Barcelona, Piados, 1994.

Galassi, Peter. Manuel Álvarez Bravo, Henri Cartier-Bressoón y Walker Evans. Documentary and Anti-Graphic Photographs, Göttingen, STEIDL, [2006].
Lozoya, Jorge Alberto (edc.). Cine mexicano, México-Barcelona-Madrid, Instituto Mexicano de Cinematografía-Lunwerg Editores, 1992.

Moyssén, Xavier. La crítica de arte en México, México, UNAM-Instituto de Investigaciones Estéticas, 1999, 2 vols.

Ortiz Monasterio, Pablo (edc.), Mirada y memoria. Archivo fotográfico Casasola.. México: 1900-1940, Madrid, Turner, 2002.

Sontag, Susan. Sobre la fotografía, Barcelona, Edhasa, 1996.

VV.AA. La fotografía del siglo XX. Museum Ludwig Colonia, Colonia, Taschen, 2005.

Alguna obras «fotográficas» de Elena Poniatowska:

Poniatowska, Elena y Mariana Yampolsky. La raíz y el camino, México, Fondo de Cultura Económica, [1985].

- y Mariana Yampolsky. Tlacoltalpan, [Verazruz], Insituto Veracruzano de Cultura, 1987.

- y Mariana Yampolsky. Estancias del olvido, [México], ABBA, 1988.

- y Amy Conger. Compañeras de México. Women Photograph Women, Riverside, University of California-UniversityArt Gallery, 1990.

- y Manuel Álvarez Bravo. Manuel Álvarez Bravo. El artista, su obra, sus tiempos, México, Banamex, 1991.

- y Ansel Adams. Frida Kablo: la cámara seducida, México, La Vaca Independiente, 1992.

- Tinísima, México, Era, 1993.

- y Graciela Iturbide. Luz y luna, las lunitas, México, Era, 1994.

- Carlos Mosiváis y Paula Haro, EZLN, México, Era, 1994.

- La soldaderas, México, Ediciones Era-Conaculta/INAH, 1999 (2a reimp. 2003).

- Mariana Yampolsky y la buganvillia, Barcelona, Plaza y Janés, 2001.

- y Raúl Ortega. De fiesta: celebraciones tradicionales en Chiapas, [Madrid], Turner, 2003.
Apunten, disparen, flash: Elena Poniatowska / Víctor Casasola Manuel Álvarez Bravo

EVANGELINA SOLTERO SÁNCHEZ 